\title{
Extensive release of an antigen associated with the sporogonic stages of Myxobolus cerebralis (Myxozoa: Myxosporea) is detected by a heterologous antibody raised to Tetracapsuloides bryosalmonae (Myxozoa: Malacosporea)
}

\author{
David J. Morris ${ }^{1}$, Mansour El-Matbouli ${ }^{2}$ and Alexandra Adams ${ }^{1}$ \\ ${ }^{1}$ Institute of Aquaculture, University of Stirling, Stirling, Scotland FK9 4LA, UK; \\ ${ }^{2}$ Institute for Zoology, Fish Biology and Fish Diseases, Faculty of Veterinary Medicine, Ludwig Maximillian University, \\ Munich, Germany
}

Key words: PKX, Tetracapsula, whirling disease, antibody

\begin{abstract}
Monoclonal antibody B4 (mAb B4) was previously developed to the myxozoan parasite Tetracapsuloides bryosalmonae Canning, Curry, Feist, Longshaw et Okamura, 1999, the causative agent of proliferative kidney disease of salmonids. Here we describe the reaction of mAb B4 against Myxobolus cerebralis Hofer, 1903, the parasite that causes 'whirling disease' in salmonids. Tissues examined were collected from experimentally infected rainbow trout Oncorhynchus mykiss (Walbaum) and the aquatic oligochaete Tubifex tubifex (O.F. Müller), the two hosts involved in the life cycle of M. cerebralis. Paraffin sections of infected rainbow trout taken at $4 \mathrm{~h}$ and 3,10,17 and 54 days post-exposure to infective $M$. cerebralis actinospores were immunohistochemically stained with mAb B4. Longitudinal sections through infected T. tubifex sampled 120 days post-exposure to $M$. cerebralis myxospores were also examined using this method. The only phase of the M. cerebralis life cycle that expressed the mAb B4 antigen was during sporogenesis in the salmonid host. The immunohistochemical staining demonstrated that the antigen was released into the tissues surrounding the spore and sporogonic stages of the parasite. The localisation of the antigen was diffuse in the fish, suggesting that the possible effect of $M$. cerebralis infection is extensive through the head tissues and not limited to areas of cartilage destruction as previously thought.
\end{abstract}

The monoclonal antibody B4 (mAb B4) was developed by Morris (1996) to Tetracapsuloides bryosalmonae Canning, Curry, Feist, Longshaw et Okamura, 1999, a commercially important myxozoan parasite affecting the culture of rainbow trout Oncorhynchus mykiss (Walbaum, 1792) in Western Europe and North America. The mAb B4 antigen is expressed by the secondary cells of the renal extrasporogonic stages and the intratubular sporogonic stages of this parasite (Marin de Mateo et al. 1996). Immunogold electron microscopy demonstrated that the antigen is released extracellularly by the secondary cells and sporogonic stages of $T$. bryosalmonae into the immediate surroundings (Morris et al. 1997). Initial experiments to examine the specificity of a range of monoclonal antibodies developed against $T$. bryosalmonae, demonstrated that only mAb B4 was heterologous, recognising the sporogonic stages of several species of Sphaerospora and one species of Myxobolus (Marin de Mateo et al. 1996, Petchsupa 2002).

Myxobolus cerebralis Hofer, 1903 is an economically and ecologically important myxosporean parasite affecting juvenile salmonids. The parasite destroys the cartilage of the infected fish resulting in cranial and spinal deformities that contribute to the fish displaying a characteristic 'whirling' swimming behaviour (Rose et al. 2000). The life cycle of $M$. cerebralis requires two hosts, a salmonid and the aquatic oligochaete Tubifex tubifex (O.F. Müller, 1774) (Markiw and Wolf 1983, Wolf et al. 1986). The development of the parasite within both of these hosts has been well documented by light and electron microscopy (El-Matbouli et al. 1995, 1999).

Previous polyclonal antibody studies on $M$. cerebralis have determined that there is an antigenic relationship between the actinospore (oligochaete) and the myxospore (salmonid) stages of the parasite's development (Markiw 1989). Studies using the immunofluorescent antibody technique (IFAT) with polyclonal antisera have further suggested that antigens associated with the $M$. cerebralis myxospores may be released by the parasites into their immediate surroundings (Hamilton and Canning 1988). Here we present the results of a study examining the ability of mAb B4 to react with $M$. cerebralis at different stages of its developmental cycle.

\section{MATERIALS AND METHODS}

Collection and preparation of tissues. Whole rainbow trout (body length 3-4 cm) were sampled $4 \mathrm{~h}, 7$ days, 8 days, 10 days and 15 days post-exposure to infective $M$. cerebralis actinospores and fixed in $10 \%$ neutral buffered formalin. The

This paper was presented at the 6th International Symposium on Fish Parasites in Bloemfontein, South Africa, 22-26 September 2003. 
head of an experimentally infected rainbow trout taken 54 days post-exposure to actinospores, was laterally bisected and fixed in Bouin's fixative. All tissues were processed and embedded in paraffin, after which sections were taken at 4-5 $\mu \mathrm{m}$. Longitudinal sections through infected T. tubifex sampled 120 days post-exposure to $M$. cerebralis myxospores were also processed using this method for immunohistochemistry.

Immunohistochemistry. Immunohistochemistry was performed on the sections using a modified protocol of Adams and Marin de Mateo (1994). De-paraffinised sections were ringed using a PAP pen and treated with $10 \%$ hydrogen peroxide in methanol, for $10 \mathrm{~min}$. After rinsing in Tris buffered saline (TBS: $0.05 \mathrm{M}$ Tris, $0.15 \mathrm{M} \mathrm{NaCl}, \mathrm{pH} 7.6$ ) they were incubated with normal goat serum diluted 1:10 (v:v) in TBS for $10 \mathrm{~min}$. The slides were tapped dry and the sections were incubated for 1 hour in a moist chamber with undiluted mAb B4 supernatant at room temperature. The sections were rinsed again with TBS and incubated with goat anti-mouse $\operatorname{IgG}$ conjugated to horseradish peroxidase (Diagnostics Scotland, Carluke, UK) for $30 \mathrm{~min}$ at room temperature. The sections were again rinsed in TBS and the chromogen Vector purple applied (Vector Laboratories, Peterborough, UK). The reaction on the positive control slide was monitored under an inverted microscope and when intense staining was noted the slides were rinsed in distilled water. The sections were counterstained using methyl green (Vector Laboratories) as recommended by the manufacturer. Negative control sections of the embedded tissues were included. These sections were tested using the above procedure, however the mAb B4 supernatant was replaced with Dulbecco's Modified Essential Medium. A positive control of kidney tissue infected with $T$. bryosalmonae was also included as well as a negative control section through a naïve rainbow trout head. All sections were examined for evidence of immunohistochemical staining and photomicrographs obtained using an MRCgrab Zeiss imaging system.

\section{RESULTS}

Examination of the control sections demonstrated that there was relatively intense non-specific staining on both the polar capsules of the actinospores in the pansporoblasts lining the intestine of the oligochaete host and the polar capsules of the myxospores in the rainbow trout. Non-specific staining was also noted on occasional sections, with some epithelial cells in the exposed trout and on the cartilage in the head of the trout. However, this staining was very faint and could easily be distinguished from the more intense staining resulting from the immunohistochemistry and was possibly an artifact from the chromogen used.

\section{Immunohistochemistry on developmental stages within oligochaete host}

Although developing pansporoblasts were clearly visible in the epithelial tissues of the intestine, no specific staining was noted upon them.

\section{Immunohistochemistry on skin and nerve stages within rainbow trout}

No specific staining was observed in any of the tissue sections containing nerve or epithelial stages of $M$. cerebralis. Using the methyl green counterstain, nerve stages could not easily be distinguished in the samples. However, large numbers of epithelial stages could clearly be identified in the $4 \mathrm{~h}$ exposed trout. This demonstrated that the nerve stages would have been present within fish sampled at later time points.

\section{Examination of head cartilage and parasite sporogenesis}

The head of the fish contained several large granulomas surrounding spores and sporogonic stages. The majority of these occurred within the lower jaw of the fish, however, discrete granulomas also occurred within, and closely associated with, the bones of the cranium. Evidence of cartilage destruction and bone deformation was also present within the head. Immunohistochemistry using $\mathrm{mAb} B 4$ resulted in a strong purple staining associated with the parasites, granulomas and areas of the neighbouring tissues (Fig. 1). The staining was diffuse within the granuloma and the immediate surrounding tissues, with the connective tissue and those areas of bone in direct contact with the granuloma being particularly intensely stained. The staining was associated with the perimysium, penetrating deep into the head muscles and areas of the anterior body musculature, in addition to the adipose tissues underlying the epidermis of the pharynx. The staining associated with the perimysium extended into and around neighbouring blood vessels. Within the blood vessels, staining occurred along the connective tissue of the adventitia and media regions of the wall of the vessel and on the intima, endothelial surfaces lining the vessels (Figs. 2a, 2b). Occasional myofibrils were also stained in the areas closest to the granuloma. Evidence of any host immunological reaction to the antigen was not observed.

When a granuloma was situated near the primary lamellae of the gills, the staining was observed to be associated with the lamellae of the gill, along the basement membrane surrounding the cartilage. In tissues directly associated with the base of the gill lamellae the staining took on a more localised pattern resembling intensely stained dots (Figs. 3a, 3b). It was unclear if these intensely stained areas represented small cells. The cartilage in occasional filaments stained with the antibody, although no corresponding pathology could be observed.

Localisation of mAb B4 was extensive throughout the lower jaw of the fish with areas staining on the connective tissue within the adipose layer below the lining of the oral cavity and connecting the adiposal tissue to the mandible. The staining in these tissues appeared to be associated with tissue damage, with the adiposal tissue becoming detached from the bone. Cross-sections through the tongue of the trout revealed a general staining associated with areas of tissue damage below the bone. This staining extended onto the surface of the tongue and onto the epithelium of the oral cavity (Fig. 4).

Areas of bone enclosing granulomas, spores and sporogonic stages of $M$. cerebralis were noted within 


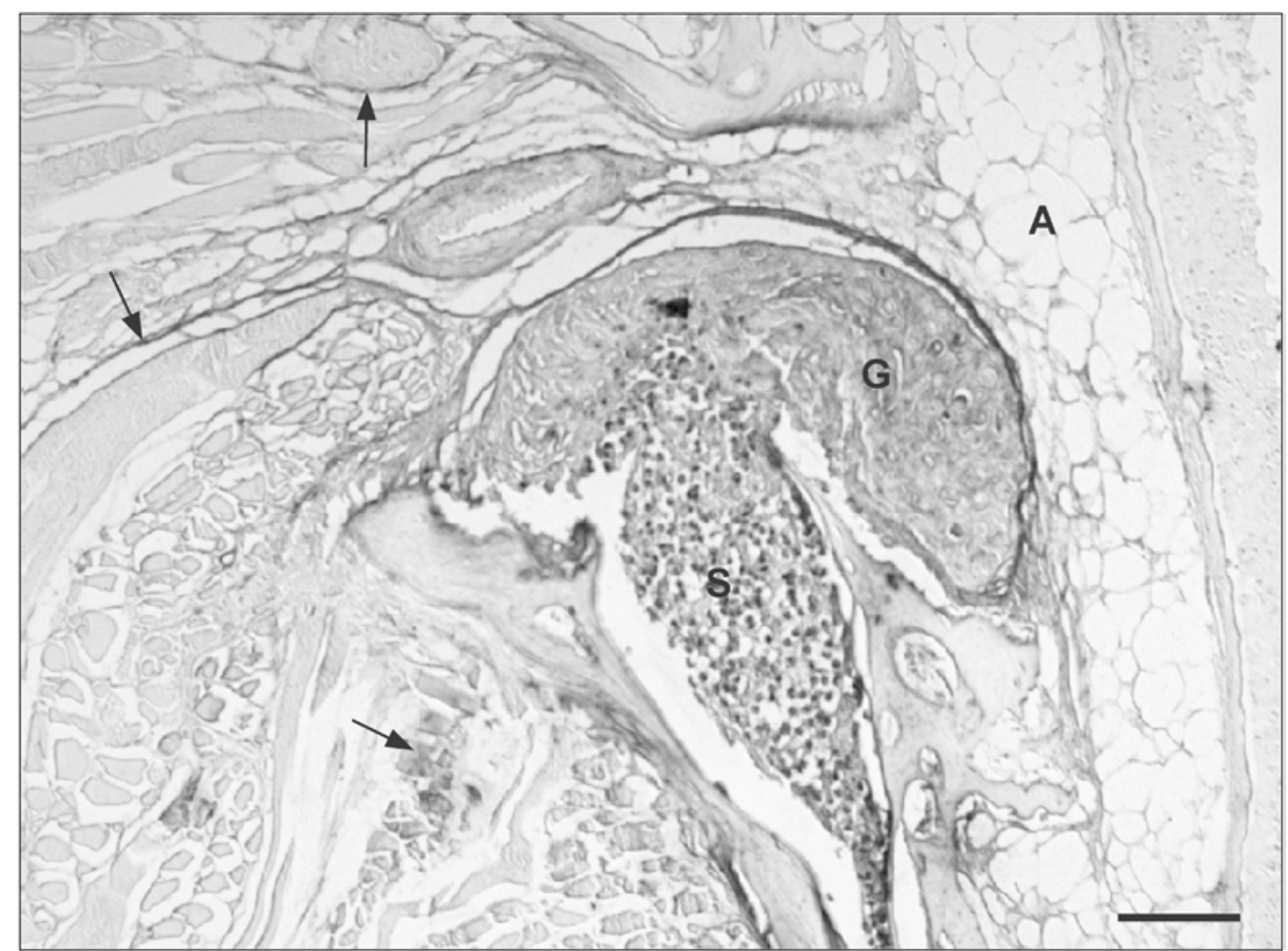

Fig. 1. Immunohistochemical staining of granuloma (G) formed around spores and sporogonic stage (S) of Myxobolus cerebralis in rainbow trout Oncorhynchus mykiss. Staining with mAb B4 is also evident throughout the neighbouring tissues, especially the perimysium (arrows) and connective tissue of the adipose tissues (A) underlying the pharynx. Scale bar $=100 \mu \mathrm{m}$.

the bones of the head. In these areas the staining was intense on the edge of the bone associated with the parasitized area but this staining did not extend into the bone. Granulomas were noted adjacent to the vestibular apparatus. Here the staining extended from the granuloma, along connective tissues and stained the basement membrane and connective tissue underlying the epithelial cells of this organ. In some areas, the connective tissue appeared to be breaking down, resulting in the epithelium of the organ to become detached from supporting structures. The staining was particularly intense in those areas where the detachment of the epithelium appeared to originate (Fig. 5).

As mentioned previously, staining within the granulomatous tissue was diffuse. However, more intense areas could be discerned in the presence of developing spores (Figs. 6a, 6b). Sporogonic stages of the parasite stained intensely around their periphery. As the spores developed so the staining increased. Mature spores appeared to be surrounded by a 'halo', where no cytoplasm was present, with the edge of the halo being intensely stained (Fig. 7). Occasionally the sporoplasm of a spore would stain. However, as the spore became detached from the surrounding tissues any staining associated with it either resided on its surface or the spore did not stain at all. From the sections examined, two single $M$. cerebralis myxospores were noted em- bedded in a gill filament and brain respectively. In these tissues staining was limited to the area of tissue immediately surrounding the spores and was not associated with any notable pathology.

\section{DISCUSSION}

Previous examinations of the antigens of Myxobolus cerebralis have focused on polyclonal antibody reactions to the spore stages of the parasite. Rabbit polyclonal antisera have been produced both to the actinospore and the myxospore stages of the parasite (Hamilton and Canning 1988, Markiw 1989). These studies have demonstrated that the spore stages of the parasite possess antigens on their surface and that some of these antigens are common to both spore types. Markiw (1989) postulated that some antigens expressed during the intraoligochaete development of $M$. cerebralis are different from those of the intrapiscine stages. The immunohistochemical staining using mAb B4 demonstrates that stage specific antigens do exist during the development of $M$. cerebralis, with mAb B4 antigen only being produced during sporogony in rainbow trout. This also corresponds with Tetracapsuloides bryosalmonae that differentially expresses mAb B4 antigen during its development within the kidney (Marin de Mateo et al. 1996, Morris et al. 1997). 


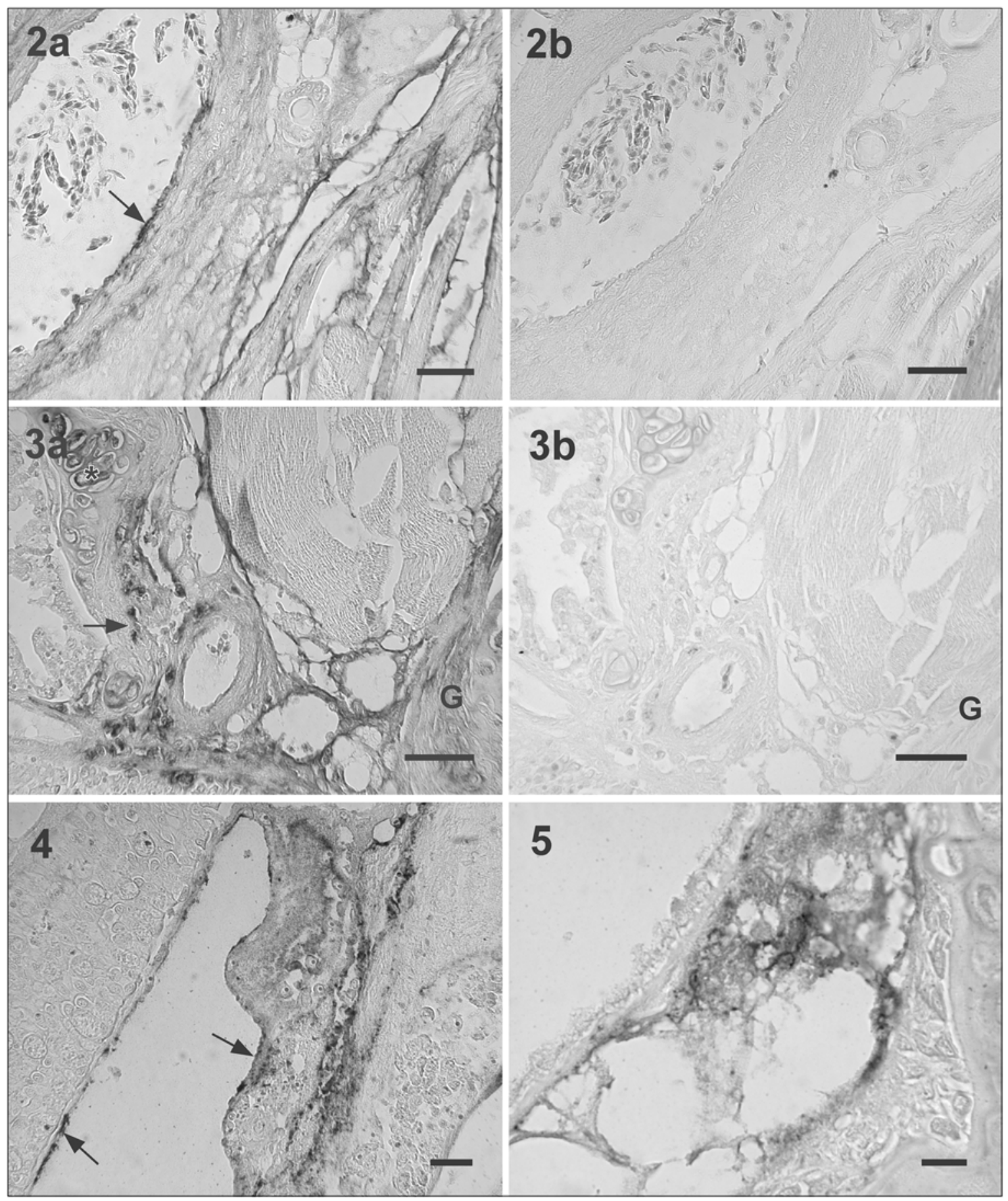

Figs. 2a-5. Immunohistochemical staining of Myxobolus cerebralis-infected rainbow trout tissues with mAb B4. Fig. 2a. Localisation of mAb B4 on perimysium, myofibrils and associated blood vessels. Arrow indicates immunohistochemical staining within the inner wall of the blood vessel. Fig. 2b. Negative control serial section of corresponding tissue to Fig. 2a. Fig. 3a. Immunohistochemical staining associated with granuloma formed near gill lamellae $(\mathrm{G})$. Antigen is localised throughout tissues and can be seen extending into the lamellae. Cartilage of the lamellae is immunostained $\left(^{*}\right)$ and intensely immunostained discrete areas can be observed (arrow). Fig. 3b. Negative control section of corresponding tissue to Fig. 3a highlighting extent of the immunohistochemical staining. Fig. 4. Tongue of rainbow trout demonstrating that the immunohistochemical staining extends from the inner tissues of the tongue onto its surface and onto the epithelium lining the pharynx (arrows). Fig. 5. Area of intense immunohistochemical staining associated with the basement membrane of the vestibular apparatus. The epithelium of the vestibular apparatus appears to be coming away from the connective tissues that hold it in place. The connective tissues in this area are heavily stained with the antibody. Scale bars: Figs. $2 a, b=30 \mu \mathrm{m}$; Figs. $3 a, b=50 \mu \mathrm{m}$; Fig. $4=15 \mu \mathrm{m}$; Fig. $5=10 \mu \mathrm{m}$. 


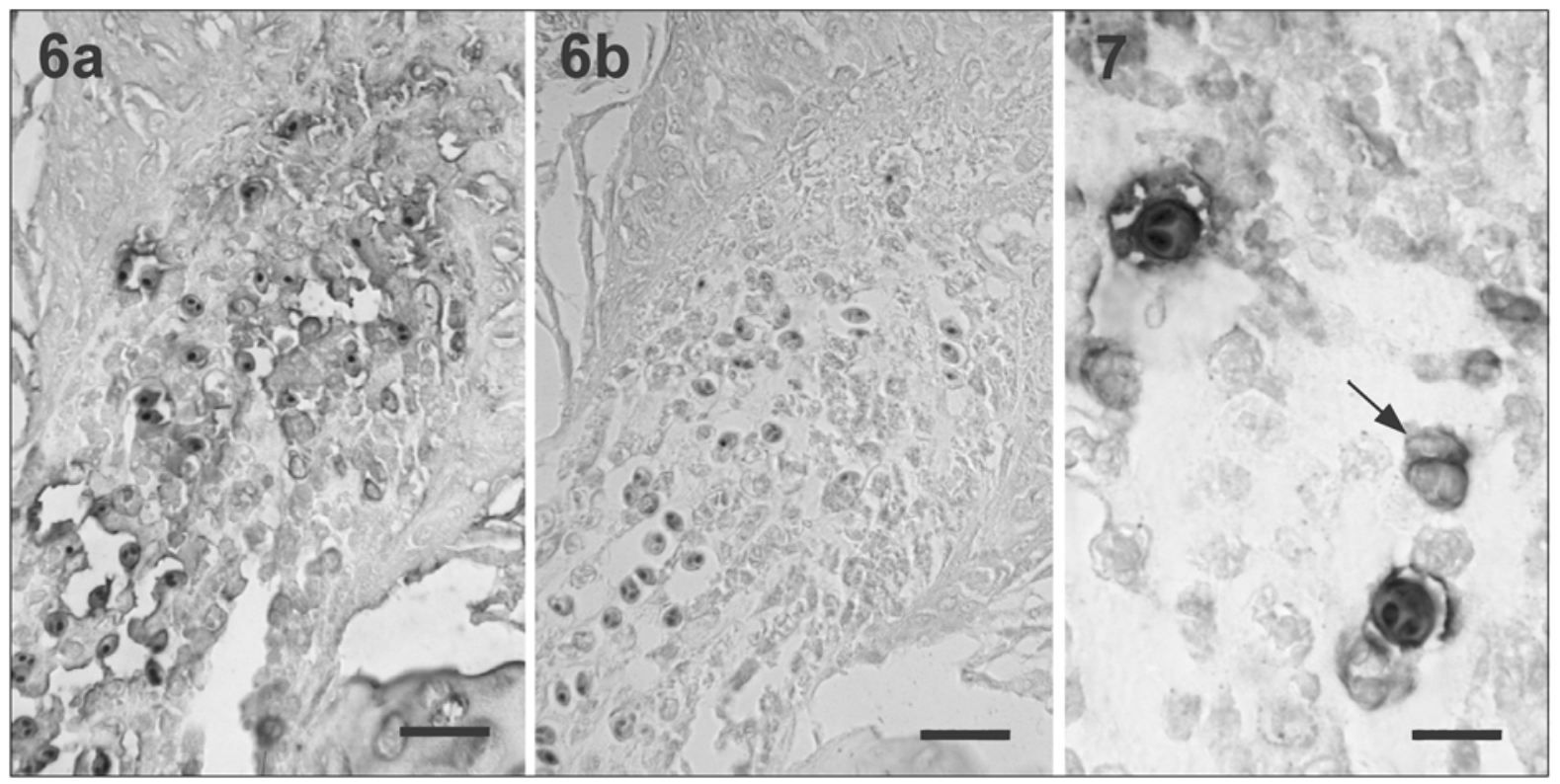

Figs. 6a-7. Immunohistochemical staining of Myxobolus cerebralis-infected rainbow trout tissues with mAb B4. Fig. 6a. Areas of intense immunohistochemical staining within a granuloma. Immunostaining is diffuse around spores. Fig. 6b. Corresponding negative control section of Fig. 6a. Note the polar capsules of spores have been stained. Fig. 7. Spores within a granuloma. Intense immunohistochemical staining is associated with their periphery. Polar capsules are non-specifically stained while relatively light immunohistochemical staining is occurring within the sporoplasm. Arrow indicates developing spores within an immunostaining cell. Scale bars: Figs. $6 \mathrm{a}, \mathrm{b}=50 \mu \mathrm{m}$; Fig. $7=10 \mu \mathrm{m}$.

Using polyclonal antibody serum raised against spores of M. cerebralis, Hamilton and Canning (1988) observed areas of cartilage fluorescing and suggested that the spores and pre-spore stages of M. cerebralis may release antigens into the host tissue. The immunohistochemical staining with mAb B4 confirms that at least one antigen is released during sporogenesis. However, in contrast to T. bryosalmonae, this release is not localised to the immediate surroundings of the parasites but is extensive, throughout the connective tissues. The localisation of the $\mathrm{mAb}$ B4 antigen indicates that it is synthesized by either the pericyte or the plasmodia enclosing the developing $M$. cerebralis spores, although occasional sporoplasms within spores were also observed to stain. As the spores become released from the surrounding matrix the staining on them decreases, with many spores only staining on their periphery or not at all. This suggests that the majority of staining observed on the spores is associated with the remains of the surrounding cell adhering to them. The nature of the release of the $\mathrm{mAb} \mathrm{B} 4$ antigen during sporogony cannot presently be determined as it may represent an active process by the parasite or be a consequence of parasite degeneration.

Reactions of trout immune sera to purified $M$. cerebralis myxospores have demonstrated that the fish produce an antibody response to this stage of the parasite's life cycle suggesting the they may have immunological relevance for developing resistance to the disease (Griffin and Davis 1978). Although, release of the mAb B4 antigen was extensive, it did not appear to be associated with any discernible host reaction. The extent of the immunostaining pervading the tissues of the head and associated body musculature indicate that, if the mAb B4 antigen is biologically active, then the effect of the parasite is not localised to the cartilage but is more pervasive through many tissues of the fish including the muscle.

The presence of single spores within the gill lamellae and the brain has not been reported before. It is possible that the location of these spores was an artefact caused by the tissue processing. However, as the staining was also localised within the tissue adjacent to the spores, it may be that they had been transported to these organs by the circulatory system.

Tetracapsuloides bryosalmonae and M. cerebralis belong to different classes within the Myxozoa. The cross-reaction of mAb B4 with these two species indicates that there may be a common antigen produced by members of this phylum. The nature of this antigen can only be speculated upon, however it is interesting to note that some immunostaining, such as that associated with the vestibular apparatus, was associated with areas of tissue damage. Further work to identify and characterise this antigen is currently being conducted.

Acknowledgements. The authors would like to thank the Department of Environment, Food and Rural Affairs (contract no. FC1111) for funding this research and Prof. H.W. Ferguson, University of Stirling, for his advice on the interpretation of anatomical structure. 


\section{REFERENCES}

ADAMS A., MARIN DE MATEO M. 1994: Immunohistochemical detection of fish pathogens. In: J.S. Stolen, T.C. Fletcher, A.F. Rowley, D.P. Anderson, S.L. Kaattari, J.T. Zelikoff and S.A. Smith (Eds.), Techniques in Fish Immunology 3. SOS publications, New Jersey, pp. 133144.

El-MATBOULI M., HOFFMANN R.W., MANDOK C. 1995: Light and electron microscopic observations on the route of the triactinomyxon-sporoplasm of Myxobolus cerebralis from epidermis into rainbow trout cartilage. J. Fish Biol. 46: 919-935.

El-MATBOULI M., HOFFMANN R.W., SCHOEL H., McDOWELL T.S., HEDRICK R.P. 1999: Whirling disease: host specificity and interaction between the actinosporean stage of Myxobolus cerebralis and rainbow trout (Oncorhynchus mykiss). Dis. Aquat. Org. 35: 1-12.

GRIFFIN B.R., DAVIS E.M. 1978: Myxosoma cerebralis: detection of circulating antibodies in infected rainbow trout (Salmo gairdneri). J. Fish. Res. Board Can. 35: 1186-1190.

HAMILTON A.J., CANNING E.U. 1988: The production of mouse anti-Myxosoma cerebralis antiserum from Percollpurified spores and its use in immunofluorescent labelling of Historesin-embedded cartilage derived from infected rainbow trout, Salmo gairdneri Richardson. J. Fish Dis. 11: 662-668

MARIN de MATEO M., McGEORGE J., MORRIS D., KENT M.L. 1996: Comparative studies of PKX and
Sphaerospora spp. from salmonids using lectin and monoclonal antibody staining techniques. J. Fish Dis. 19: 55-63.

MARKIW M.E. 1989: Salmonid whirling disease: myxosporean and actinosporean stages cross-react in direct fluorescent antibody test. J. Fish Dis. 12: 137-141.

MARKIW M.E., WOLF K. 1983: Myxosoma cerebralis (Myxozoa: Myxosporea) etiologic agent of salmonid whirling disease requires tubificid worm (Annelida: Oligochaeta) in its life cycle. J. Protozool. 30: 561-564.

MORRIS D.J. 1996: Studies on proliferative kidney disease using monoclonal antibody probes. $\mathrm{PhD}$ thesis, University of Stirling, UK, $180 \mathrm{pp}$.

MORRIS D.J., ADAMS A., RICHARDS R.H. 1997: Studies of the PKX parasite in rainbow trout via immunohistochemistry and immunogold electron microscopy. J. Aquat. Anim. Health 9: 265-273.

PETCHSUPA N. 2002: Studies on proliferative kidney disease with particular reference to vaccine development. $\mathrm{PhD}$ thesis, University of Stirling, UK, $270 \mathrm{pp}$.

ROSE J.D., MARRS G.S., LEWIS C., SCHISLER G. 2000: Whirling disease behaviour and its relation to pathology of brain stem and spinal cord in rainbow trout. J. Aquat. Anim. Health 12: 107-118.

WOLF K., MARKIW M.E., HILTUNEN J.K. 1986: Salmonid whirling disease: Tubifex tubifex (Müller) identified as the essential oligochaete in the protozoan life cycle. J. Fish Dis. 9: 499-501.

Accepted 20 April 2004 